Published by Al-Nahrain College of Medicine P-ISSN 1681-6579

E-ISSN 2224-4719

Email: iraqijms@colmed-alnahrain.edu.iq

http://www.colmed-alnahrain.edu.iq

http://www.iraqijms.net

Iraqi JMS 2018; Vol. 16(2)

\title{
Amyloid Precursor Protein Immunohistochemical Changes in The Newborn Mice Frontal and Parietal Cerebral Cortices Affected by Prenatal Exposure to Ketamine
}

\author{
Mohanad S. Najm MSC, Hayder J. Mubarak ${ }^{1} P h D$, Lamia H. Mohammed ${ }^{1} M S C$ \\ ${ }^{1}$ Dept. of Human Anatomy, College of Medicine, Al-Nahrain University, Baghdad, Iraq
}

\begin{abstract}
Background Ketamine is N-methyl-D-aspartate (NMDA) receptors blocking drug, it affects the cerebral cortex and play an essential role in learning and memory. Amyloid $\beta(A \beta)$ is a cleavage product of a large, trans-membrane protein, termed amyloid precursor protein (APP); it may have a role in controlling synaptic activity.

Objective To investigate the immunohistochemical beta APP reaction in newborn mice frontal and parietal cerebral cortices after prenatal exposure to therapeutic doses of ketamine as an attempt for scientific judgments of making better understanding for effects of ketamine on developing brain, which may help to reduce adverse effects.

Methods Thirty pregnant mice were divided into two groups named experimental and control groups (15 mice for each groups). The experimental group animals were injected intraperitoneally with $50 \mathrm{mg} / \mathrm{kg}$ ketamine, the control group animals were injected with intraperitoneal distilled water. Paraffin sections of newborn mice frontal and parietal cortices were stained immunohistochmically with anti-APP antibodies.

Results The immunohistochemical labeling in the experimental group showed scattered clumps of brown staining distributed randomly in the cerebral cortex. The brown stained deposits vary also in shape and size, the larger and more intense staining was seen in the more superficial layers of the frontal cortex. The statistical analysis found non-significant differences in staining pattern between frontal and parietal cortices of control group, while significant differences were found between frontal and parietal cortices in experimental group.

Conclusion The immunohistochemical APP reactivity showed different intensities and different morphology in the frontal and parietal cortices in the all experimental group animals were that injected with ketamine in this study. These differences could be related to the requirement of this substance in repair and differentiation of the developing NMDA dependent interneuron impaired by prenatal ketamine exposure.

Keywords Frontal cortex, parietal cortex, amyloid precursor proteins, ketamine, prenatal, immnuohistochemistry

Citation

Najm MS, Mubarak HJ, Mohammed LH. Amyloid precursor protein immunohistochemical changes in the newborn mice frontal and parietal cerebral cortices affected by prenatal exposure to ketamine. Iraqi JMS. 2018; 16(2): 191-200. doi: 10.22578/IJMS.16.2.11
\end{abstract}

List of abbreviations: $A b=$ Beta amyloid, $A D=$ Alzheimer's disease, $\mathrm{APP}=$ Amyloid precursor protein, $\mathrm{CNS}=$ Central nervous system, $\mathrm{DAB}=$ Diaminobenzidine, $\mathrm{IHC}=$ Immunohistochemistry, $\mathrm{IP}=$ Intrapritonial administration, $\mathrm{NIH}=$ National institute of health, NMDA $=\mathrm{N}$-methyl-D-aspartate, SPSS $=$ Statistical package of social sciences

\section{Introduction}

K etamine is an N-methyl-D-aspartate (NMDA) receptor blocker ${ }^{(1)}$, it is -commonly used for induction and maintenance of anesthesia ${ }^{(2)}$ chiefly in the developing world ${ }^{(3)}$. The NMDA receptors are present in high concentration in the cerebral cortex and play an essential role in learning and memory, and there is an evidence suggesting that any changes in NMDA receptor function have an impact on learning and memory abilities ${ }^{(4)}$.

The trial studies in animals have shown that exposure of the anesthetic agents during developmental periods can lead to neuronal apoptosis or neurodegeneration ${ }^{(5)}$. 
The laboratory models intend anesthetic interactions with neurodegenerative mechanisms, such as those linked to the onset and progression of Alzheimer's disease (AD) ${ }^{(5)}$. The theories of neurodegeneration in $A D$ mainly focus on the toxic effects of aggregated amyloid $\beta(A \beta)$ peptide oligomers that result from intramembranous proteolysis of the transmembrane protein amyloid precursor protein (APP) ${ }^{(6)}$.

There are Several lines of evidence indicate that $A \beta$ may have a role in controlling synaptic activity ${ }^{(7)}$.

This study aimed to investigate the immunohistochemical beta APP expression in newborn mice frontal and parietal cerebral cortices after prenatal exposure to therapeutic doses of ketamine as an attempt for scientific judgments of making better understanding for effects of ketamine on developing brain which may help to reduce adverse effects.

\section{Methods}

The animals used in this study were obtained from Laboratory Animal House at College of Medicine, Al-Nahrain University. A total of (30) pregnant adult female mice (mus musculus) aged (8-12) weeks were used in this study. Weight of the animals was between (20- 40 gm).

Checks the mouse estrous cycle. The mating occurs after putting two females per one male in one cage.

After mating, pregnancy was confirmed the following morning by finding vaginal plugs and this was considered as day 0 of gestation ${ }^{(8)}$.

All animals were treated according to National Institute of Health (NIH) Guidelines for the Care and Use of laboratory animals ${ }^{(8)}$.

The 30 pregnant mice were divided into two groups; I namely experimental group and II namely control group (15 Mice for each group). The pregnant mice of experimental group were injected intraperitoneally with a single shot of $50 \mathrm{mg} / \mathrm{kg}$ ketamine hydrochloride ${ }^{(9)}$ on the $5^{\text {th }}$, $10^{\text {th }}, 15^{\text {th }}$, and $20^{\text {th }}$ days of pregnancy.
The control group mice were injected intraperitoneally with distilled water on the same gestational days.

Each female mouse delivered (6-10) neonates; after delivery neonates were selected randomly.

The one-day old neonate was decapitated after delivery and removed the skin of head, but the skull shield was not removed.

The newborn brain was fixed in $10 \%$ formalin, the fixed tissues were then submitted for routine paraffin embedding process including dehydration, clearing, infiltration, and embedding ${ }^{(10)}$. Sections of $5 \mu \mathrm{m}$ thickness of cerebral tissue were taken and properly laid down on the surface of hot water $\left(40^{\circ} \mathrm{C}\right)$. The sections were then collected on clean strong positive slides (AFCO). From each paraffin tissue block. Each slide was contained 4 sections and was taken for immunohistochemical staining.

The immunohistochemical staining kits, provided by $\mathrm{Abcam}^{\circledR}$, contained rabbit polyclonal antibody to Amyloid Precursor Protein clone (ab15272) and Rabbit specific DAB, (ab64261) detection kit from Abcam ${ }^{\circledR}$.

The sections were examined under light microscopy (Genex, USA) to localize and determine the pattern of immunohistochemical expression of AntiAmyloid Precursor Protein and then images were captured by camera (5 mega pixels, Genex, USA) equipped with in the genex light microscope.

Statistical Package for the Social Sciences (SPSS) version 22 company by (IBM) was a software used for statistical evaluation and in dependent ( $t$ ) test was used for analysis of mean values of strong positive Pixel Count Algorithm obtained by the application Aperio Image Scope software on Amyloid Precursor Protein immunohistochemical reactivity in the frontal and parietal cortices of neonates' mice in both experimental and control groups.

\section{Results}

The immunohistochemical labeling in experimental group showed scattered clumps of brown staining distributed randomly in the 
cerebral cortex, these clumps were localized in the extracellular matrix and having different intensities. The brown depositions varied also in size in superficial layer, however; larger and more intense accumulations of the immunohistochemical reactivity were seen in the more superficial layers of the frontal cortex (Figure 1).

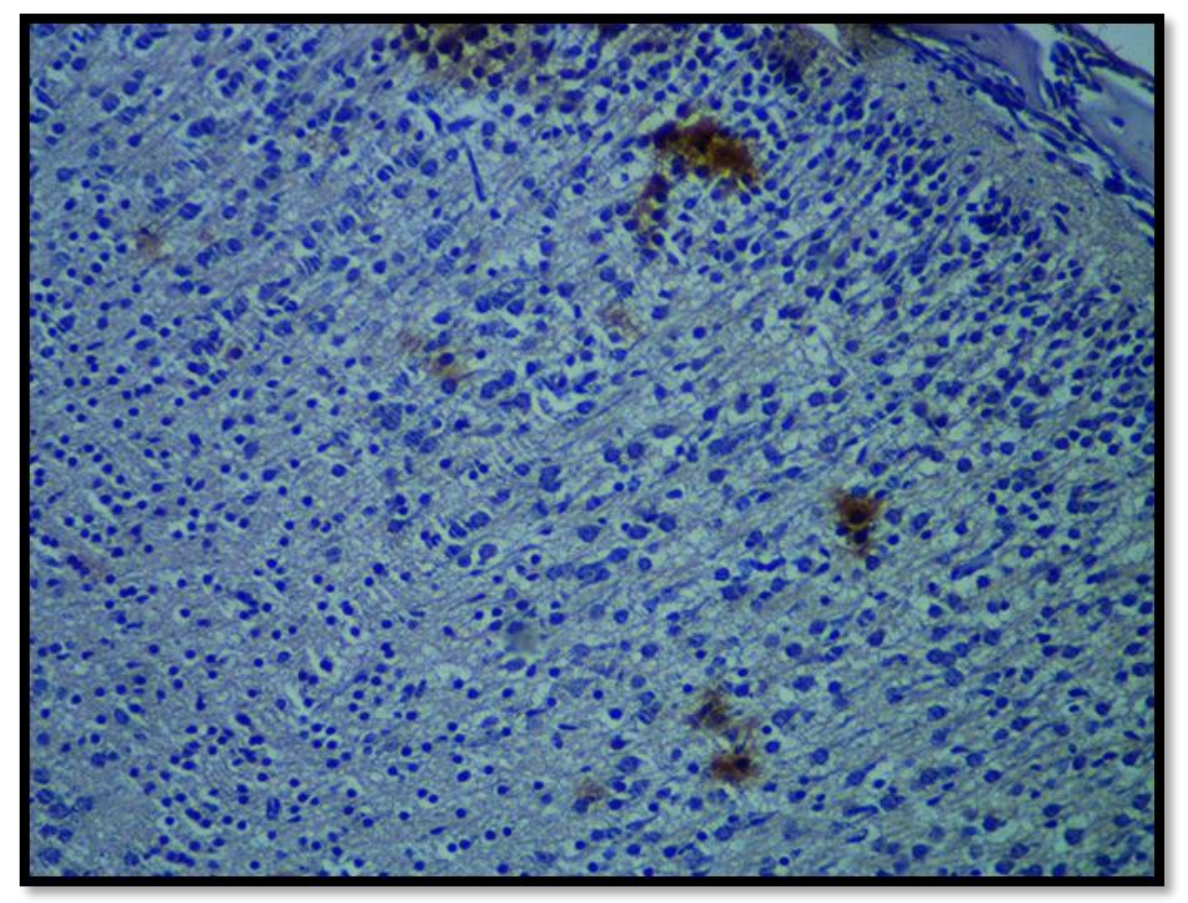

Figure 1. Sagittal paraffin section. Frontal cortex of the neonate mouse of the experimental group. The low magnification immunohistochemical labeling showed scattered clumps of brown staining distributed randomly in the frontal cortex, these brown staining was localized in the extracellular matrix and having different intensities and more intense accumulations of the immunohistochemical reactivity was seen in the superficial layers of the frontal cortex. Immunohistochemical Anti-APP staining (X200)

APP immunohistochemical reaction in the frontal and parietal cortices of newborn mice in control group

The evaluation of the counted mean values in the frontal cortex of neonate mice of control groups revealed statistically non-significant difference compared to parietal cortex of the same group (Figures 2 and 3 ).

The mean value of the number of strongly positive pixels was $(1.6818 \pm 7.88)$ in frontal cortices; the mean value in parietal cortices of control group was $(0.7273 \pm 3.19)$.

The mean value comparison between frontal and parietal cortices in the control group showed statistically non-significant difference and $p$ values of the mean counted pixels was $\geq$ 0.602 of the mean counted pixels (Table 1). Both these cortices showed very weak immunohistochemical reactivity. 

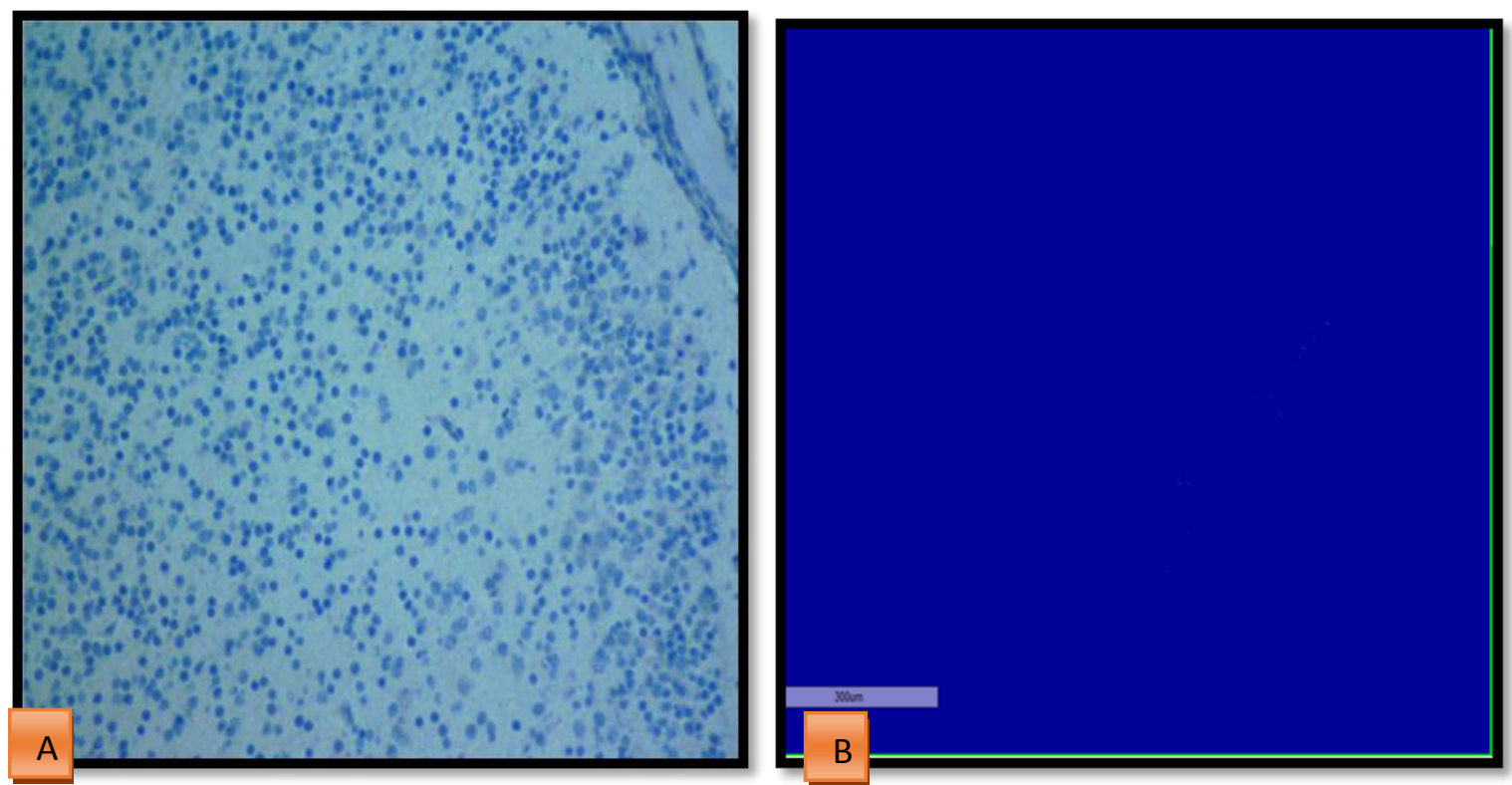

Figure 2. (A) APP reactivity in frontal cerebral cortex of neonate mice from control group. The APP negative stain is seen in all layer of cerebral frontal cortex. X 200 (B) The snap shoot as analyzed by Aperio positive pixel count algorithm

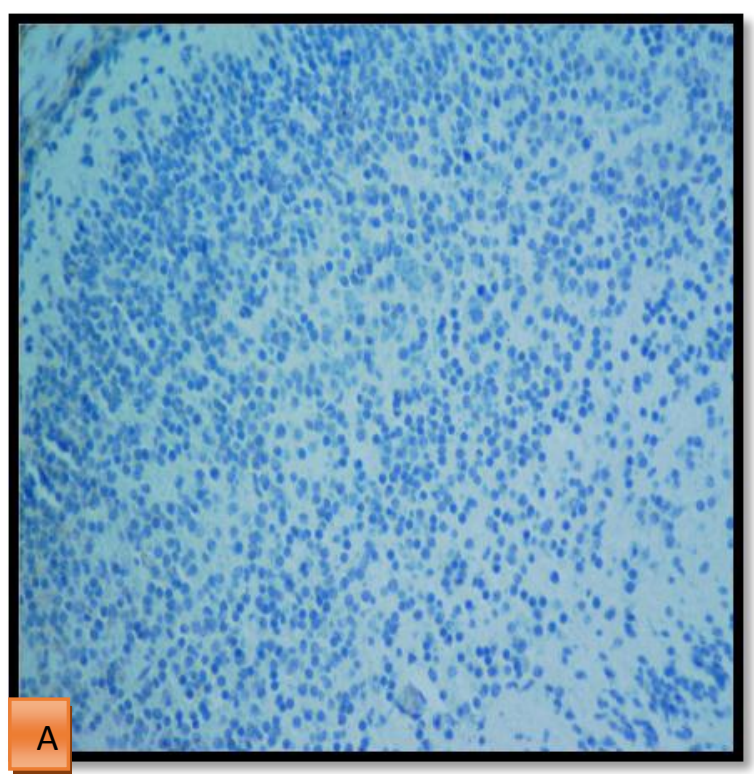

The APP immunohistochemical reaction in the frontal and parietal cortices of newborn mice in experimental group

The mean of strong positive pixel in the frontal cortex was higher than the mean of parietal cortex experimental in groups (Figure 4).

The estimation of mean values of staining intensity for the Amyloid precursor protein

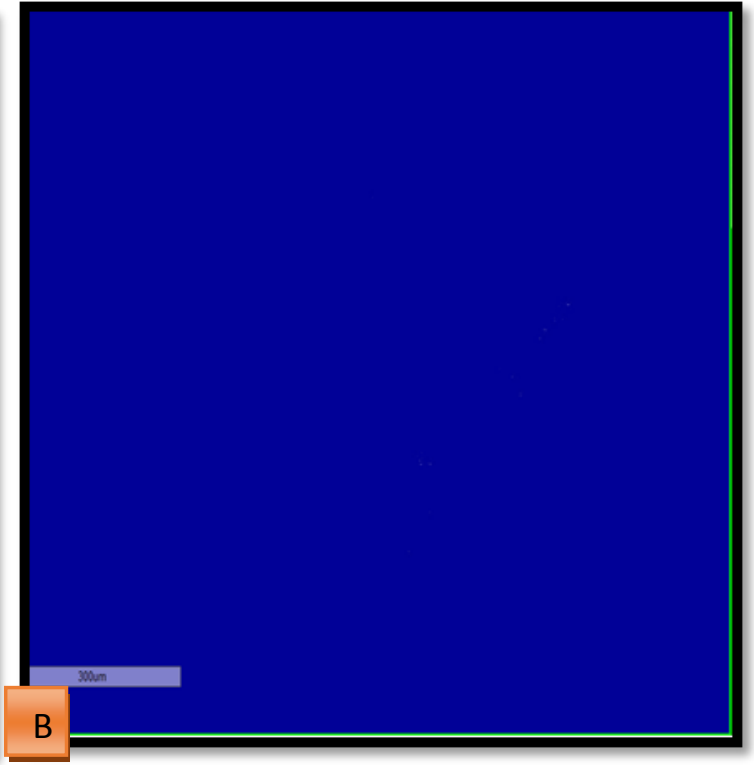

immunohistochemical reaction in the frontal and parietal cerebral cortices of the neonate mice of experimental group showed that the mean value from the neonate frontal cortices is $9734.05 \pm 1074.82$, and the mean value of parietal cortices is $948.82 \pm 1168.22$ (Figures 5,6 and 7). 
The mean of the strong positive pixel obtained from the frontal cortices showed statistically significant difference from those of the parietal cortices experimental groups $(\mathrm{P} \leq 0.000)$ (Table 1).

Table 1. The mean strong positive pixel obtained by the Aperio Image Scope analysis of frontal and parietal cerebral cortices sections of newborn mice

\begin{tabular}{|c|c|c|c|}
\hline \multicolumn{2}{|l|}{ Group } & Mean $\pm S D$ & P value \\
\hline $\begin{array}{c}\text { Frontal and parietal cortices } \\
\text { of control group }\end{array}$ & $\begin{array}{l}\text { Frontal cortex } \\
\text { Parietal cortex }\end{array}$ & $\begin{array}{c}1.69 \pm 7.89 \\
0.73 \pm 3.2 \\
\end{array}$ & $\begin{array}{c}0.602 \\
* \text { (not-significant) }\end{array}$ \\
\hline $\begin{array}{c}\text { Frontal and parietal cortices } \\
\text { of experimental group }\end{array}$ & $\begin{array}{l}\text { Frontal cortex } \\
\text { Parietal cortex }\end{array}$ & $\begin{array}{c}9734.05 \pm 1074.82 \\
948.82 \pm 1168.22 \\
\end{array}$ & $\begin{array}{c}0.000 \\
* \text { (significant) }\end{array}$ \\
\hline $\begin{array}{c}\text { Frontal cortices of } \\
\text { experimental and control } \\
\text { groups }\end{array}$ & $\begin{array}{l}\text { Frontal cortex of } \\
\text { experimental group } \\
\text { Frontal cortex of } \\
\text { control group }\end{array}$ & $\begin{array}{c}9734.05 \pm 1074.82 \\
1.682 \pm 7.89\end{array}$ & $\begin{array}{c}0.000 \\
* \text { (significant) }\end{array}$ \\
\hline $\begin{array}{l}\text { Parietal cortices of } \\
\text { experimental and control } \\
\text { groups }\end{array}$ & $\begin{array}{l}\text { Parietal cortex of } \\
\text { experimental group } \\
\text { Parietal cortex } \\
\text { control group }\end{array}$ & $\begin{array}{c}948.82 \pm 1168.22 \\
0.73 \pm 3.2\end{array}$ & $\begin{array}{c}0.000 \\
* \text { (significant) }\end{array}$ \\
\hline
\end{tabular}

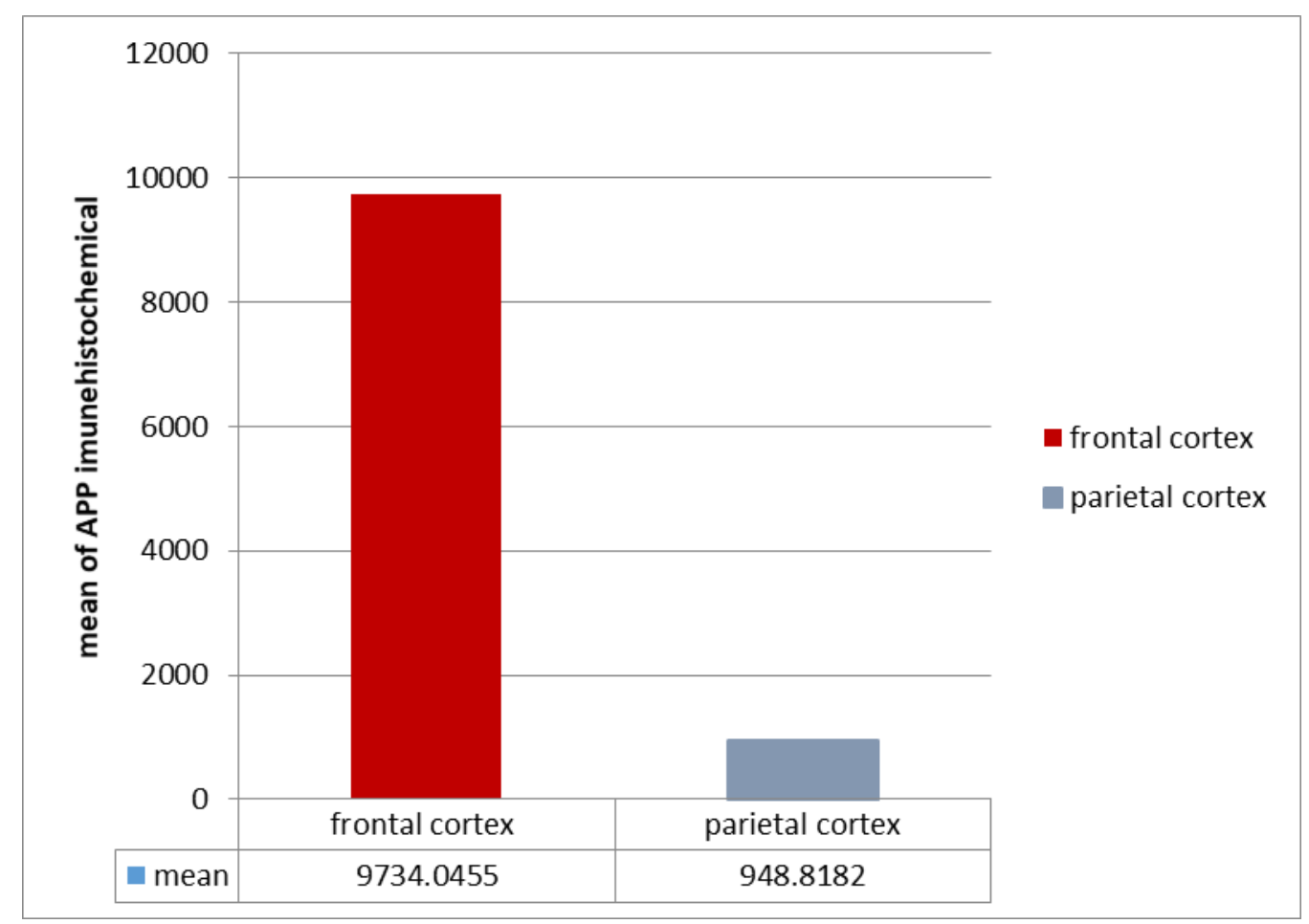

Figure 4. The values of APP immunohistochemical marker reactivity obtained from frontal and parietal cortical section in newborn mice of the experimental groups 

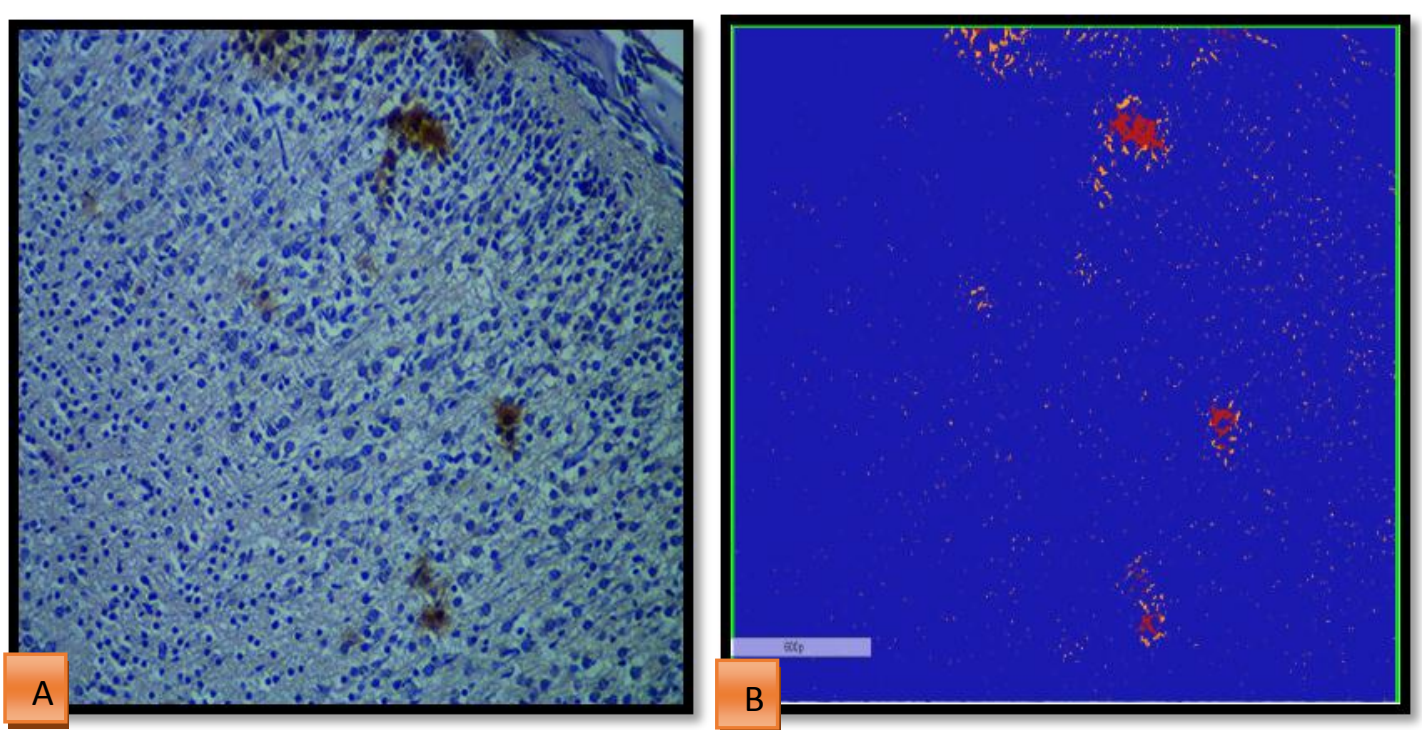

Figure 5. (A) sagittal section APP in immunohistochemical reactivity in frontal cerebral cortex of neonate mice from experimental group. APP positive stain is seen in all layer of cerebral frontal cortex. X 200 (B) The snap shoot as analyzed by Aperio Positive Pixel Count Algorithm
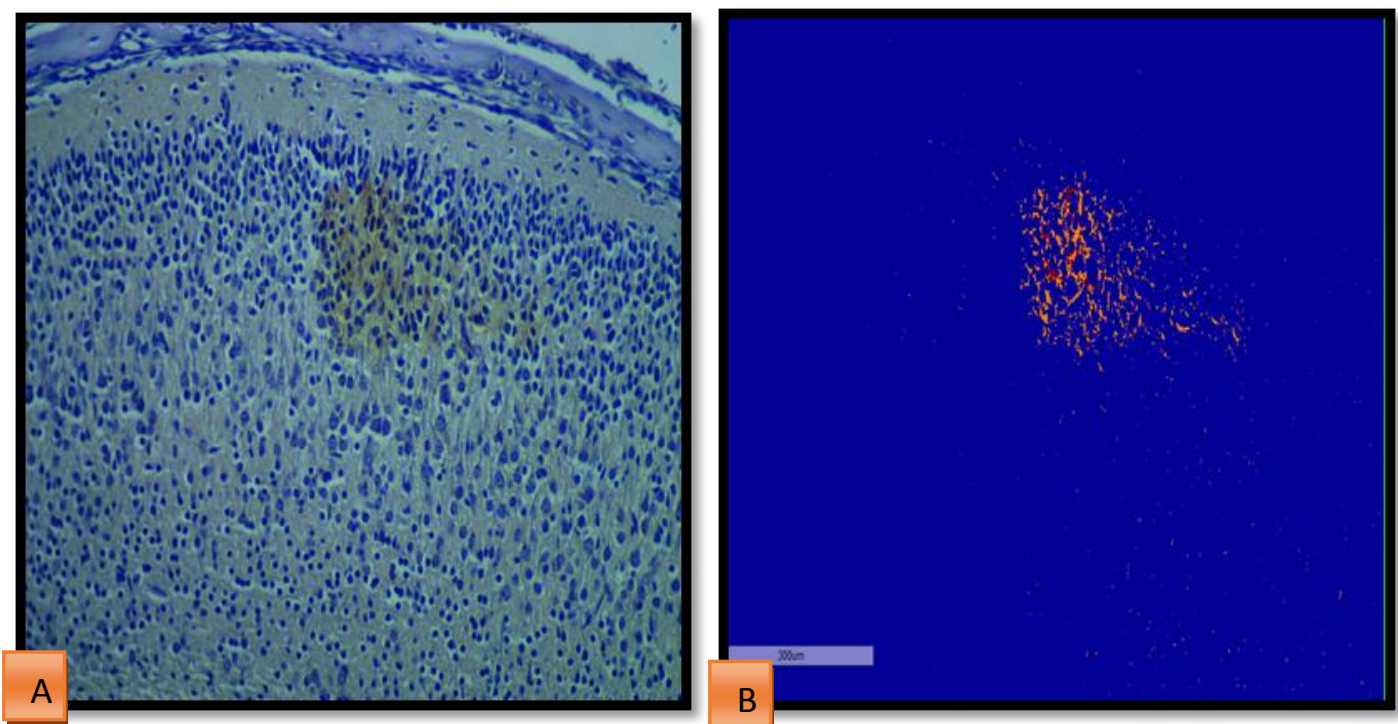

Figure 6. (A) sagittal section APP in immunohistochemical reactivity in frontal cerebral cortex of neonate mice from experimental group. APP positive stain is seen in all layer of cerebral frontal cortex. X 200 (B) The snap shoot as analyzed by Aperio Positive Pixel Count Algorithm 
Statistical evaluations of APP immunohistochemical reaction between frontal cortices of experimental group and control group

The statistical analysis of the values of the strongly positive pixels obtained from evaluation of APP immunohistochemical expression of on neonate mice frontal cortices of experimental and control group showed that the mean of strong positive pixels in frontal cortices of experimental group is $9734.05 \pm 1074.82$ and mean of strong positive pixels in control group is $1.69 \pm 7.89$. This difference was statistically significant $(P \leq$ 0.000) (Table 1).

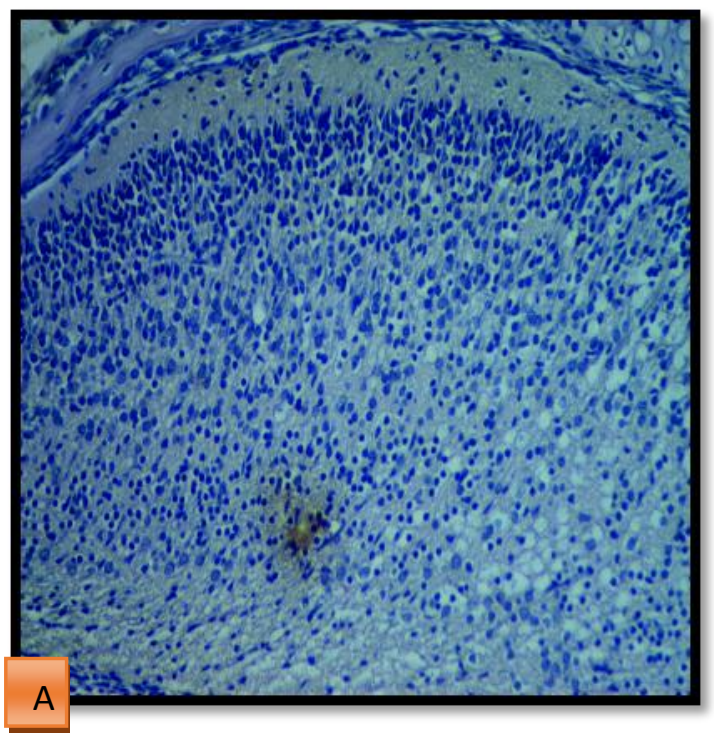

Statistical evaluations of APP immunohistochemical reaction between parietal cortices of experimental group and control group

The mean values of strong positive pixel of parietal cortices of experimental group were the highest mean value when compared to parietal cortices of control groups. The mean number of the strongly positive pixels of immunohistochemical reaction of parietal cortex of mice that was injected with ketamine is $948.82 \pm 1168.22$, while the mean of strong positive pixel of parietal cortex of mice inject with distal water is $0.73 \pm 3.2$.

The differences between the treated and control group were statistically significant $(p \leq$ 0.000) (Table 1).

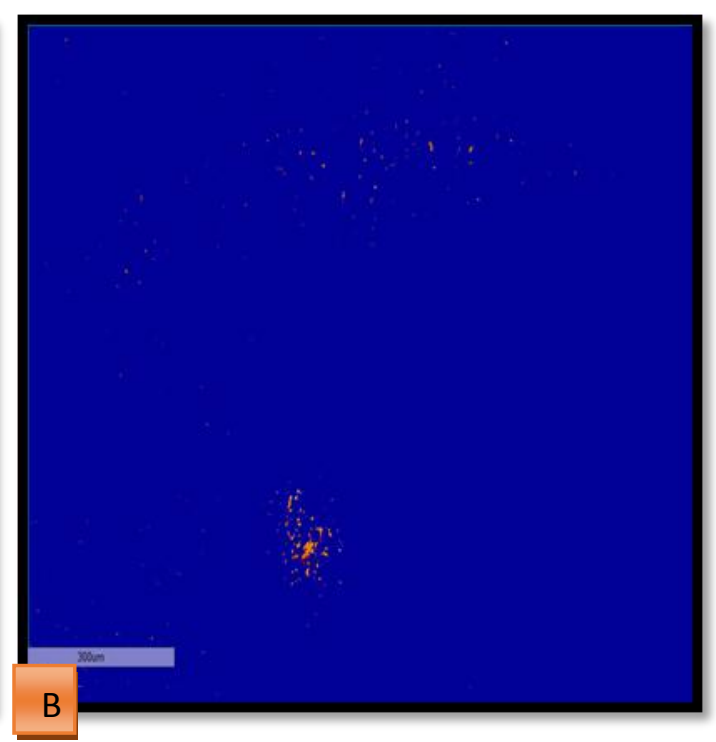

Figure 7. (A) sagittal section APP in immunohistochemical reactivity in parietal cerebral cortex of neonate mice from experimental group. APP positive stain is seen in all layer of cerebral frontal cortex. X 200 (B) The snap shoot as analyzed by Aperio Positive Pixel Count Algorithm

\section{Discussion}

The adverse effects of ketamine had been investigated extensively in many researches. Different aspects were considered in regard to neonatal and prenatal consequences of ketamine on the developing brain. Variables appraisals were done that demonstrated changes as neuronal apoptosis, synaptic transmission and plasticity, and deficits in learning-related behaviors ${ }^{(11)}$.

The immunohistochemical APP reactivity showed different intensities in the frontal cortex of the animals involved in this study that were prominently noticeable compared to the parietal cortex. This conclusion has been confirmed by the statistical evaluations of the 
mean values of strongly positive pixels algorithm found in this study.

This result simulates the histological changes occurring in the cerebral cortex of rat affected by prenatal ketamine exposure, massive histological changes seen in frontal cortex compared to parietal cortex ${ }^{(12,13)}$. Also, the regional variability of APP accumulation found in this study was highly significant in the frontal cortex, which indicates more susceptibility of frontal cortex to ketamine's compared to parietal cortex. The possible explanation of this agreement is the frequent exposure to ketamine though out pregnancy as a common contributing factor to frontal cortical pathology in this study and that was done during the other experimental procedures ${ }^{(13)}$.

The cortical lamina variability of APP accumulation after prenatal exposure to ketamine in this study was not seen in experimental researches considering neuroapoptotic consequences of prenatal ketamine exposure. It was reported in previous literatures that Ketamine have more prominent damaging effects on the fetal than neonatal brain. This speculation was implicated in both clinical anesthesia and drug abuse precautions (13). This assumption could also be adopted according to the results of our study as the cortex of fetuses was massively affected by ketamine exposure of pregnant mice. Further researches could be done in future to compare the significance of ketamine exposure of neonate but with fetus.

The accumulation of APP in this study was more marked in the superficial lamina at the frontal cortex. The APP is an integral membrane protein concentrated in the synapses of neurons. It had been implicated as a regulator of synapse formation, the mostsubstantiated role for APP is in synaptic formation and repair (14). The study of Brambrink et al. (2012) ${ }^{(13)}$ reported that none of the ketamine-exposed neonate brains showed a laminar pattern of cell death in any specific layers of the cortices. However, the laminar-specificity of ketamine-induced changes in the frontal cortex was reported by Jeevakumar et al. (2014) ${ }^{(15)}$ when ketamine was administered during the first 2 postnatal weeks, these changes were attributed to the effect of ketamine on the maturation of NMDA dependent of interneurons ${ }^{(16)}$. The distribution of these interneurons across layers of the rodent cortex was found to be highest in layer $5^{(17)}$, thus layer 5 does not show significant functional impairment by NMDA dependent of interneurons cellular loss caused Ketamine exposure compared to the superficial layers $2 / 3^{(15)}$. This interpretation is supported by the reports of previous studies that systemic injection of the NMDA receptor antagonists significantly increased the drug adverse outcome (including apoptosis) in rodent pups (18).

APP expression was suggested to be upregulated during neuronal differentiation and after neuronal injury ${ }^{(19)}$. The more AAP in superficial lamina explored in this study could be related to the requirement of this substance in repair and differentiation of the developing NMDA dependent interneuron in the superficial lamina that were impaired by prenatal ketamine exposure. The synapses formation associated with the increased dendritic branching in the frontal cortex affected by ketamine may be regulated by accumulations of AAP in the frontal cortex. The impaired maturation of these interneurons in the deeper lamina of the frontal cortex in mice does not have functional consequences due to higher percentage of these neurons in the deep lamina that balances the deficit in differentiation of these interneurons caused by prenatal ketamine exposure. This speculation supported the conclusions reported by Jeevakumar et al. (2014) ${ }^{(15)}$.

The APP immunohistochemical accumulation in mice cerebral cortex after prenatal exposure to ketamine represented a developmental requirement of cortical tissue during development needed to provide the necessary adaptive functional maturation. These developmental requirements for APP aggregation could involve functional demands including synaptogenesis and neuronal network formation (20), neurite growth, neuronal adhesion and axonogenesis ${ }^{(21)}$.

APP proteolysis generates beta amyloid $(A \beta)$, which is the primary component of amyloid 
plaques found in the brains of Alzheimer's disease patients ${ }^{(22)}$. The possibility of pathological sequel of the accumulated APP in the cerebral cortex after prenatal ketamine exposure in post-pubertal life could not be excluded.

This study concluded that the immunohistochemical APP reactivity showed different intensities and different morphology in the frontal and parietal cortices of the animals involved in this study that was prominently noticeable compared to the parietal cortex, these differences could be related to the requirement of this substance in repair and differentiation of the developing NMDA dependent interneuron impaired by prenatal ketamine exposure.

The impaired maturation of these interneurons in the deeper lamina of the frontal cortex in mice does not have functional consequences due to higher percentage of these neurons in the deep lamina that balances the deficit in differentiation of these interneurons caused by prenatal ketamine exposure.

\section{Acknowledgments}

Regard and gratefulness should be presented to the staff members Department of Human Anatomy at the College of Medicine, AlNahrain University for their assistance and cooperation.

\section{Authors contribution}

Najm: The MSc. candidate performing the laboratory research work. Dr. Mubarak: The advisor of the research performing the interpretation of the results. Mohammed: Assist for performing production of the statistical results.

\section{Conflict of interest}

The authors disclose no any financial and personal relationships with other people or organizations that inappropriately influence (bias) our work.

\section{Funding}

The research funding was provided by the authors.

\section{References}

1. Wang C, Sadovova N, Hotchkiss C, et al. Blockade of $\mathrm{N}$-methyl-D-aspartate receptors by ketamine produces loss of postnatal day 3 monkey frontal cortical neurons in culture. Toxicol Sci. 2006; 91(1): 192-201. doi: 10.1093/toxsci/kfj144.

2. Chan $W H$, Sun $W Z$, Ueng $T H$. Induction of rat hepatic cytochrome $\mathrm{P}-450$ by ketamine and its toxicological implications. J Toxicol Environ Health A. 2005; 68(1718): 1581-97. doi: 10.1080/15287390590967522.

3. Craven R. Ketamine. Anaesthesia. 2007; 62 Suppl 1: 48-53. doi: 10.1111/j.1365-2044.2007.05298.x

4. Magnusson KR, Brim BL, Das SR. Selective vulnerabilities of $\mathrm{N}$-methyl-D-aspartate (NMDA) receptors during brain aging. Front Aging Neurosci. 2010; 2: 11. doi: 10.3389/fnagi.2010.00011.

5. Hudson $A E$, Hemmings $H C$ Jr. Are anaesthetics toxic to the brain? Br J Anaesth. 2011; 107(1): 30-7. doi: 10.1093/bja/aer122.

6. Tanzi RE, Bertram L. Twenty years of the Alzheimer's disease amyloid hypothesis: a genetic perspective. Cell. 2005; 120(4): 545-55. doi: 10.1016/j.cell.2005.02.008.

7. Pearson HA, Peers C. Physiological roles for amyloid $\beta$ peptides. J Physiol. 2006; 575(Pt 1): 5-10. doi: 10.1113/jphysiol.2006.111203.

8. Suckow MA, Danneman P, Brayton C. The laboratory mouse. USA: CRC Press Inc; 2001.

9. Hahn N, Eisen RJ, Eisen L, et al. Ketaminemedetomidine anesthesia with atipamezole reversal: practical anesthesia for rodents under field conditions. Lab animal. 2005; 34(2): 48-52. doi: 10.1038/laban0205-48.

10. Bancroft J, Suvarna S, Layton C. Bancroft's theory and practice of histological techniques. China: Churchill living stone; 2013.

11. Servick K. Researchers struggle to gauge risks of childhood anesthesia. Science. 2014; 346(6214): 1161-2. doi: 10.1126/science.346.6214.1161.

12. Zhao T, Li C, Wei W, et al. Prenatal ketamine exposure causes abnormal development of prefrontal cortex in rat. Sci Rep. 2016; 6: 26865. doi: 10.1038/srep26865.

13. Brambrink AM, Evers AS, Avidan MS, et al. Ketamineinduced neuroapoptosis in the fetal and neonatal rhesus macaque brain. Anesthesiology. 2012; 116(2): 372-84. doi: 10.1097/ALN.0b013e318242b2cd.

14. Wang $Q$, Shen FY, Zou R, et al. Ketamine-induced apoptosis in the mouse cerebral cortex follows similar characteristic of physiological apoptosis and can be regulated by neuronal activity. Mol Brain. 2017; 10(1): 24. doi: 10.1186/s13041-017-0302-2.

15. Jeevakumar V, Kroener S. Ketamine administration during the second postnatal week alters synaptic properties of fast-spiking interneurons in the medial prefrontal cortex of adult mice. Cereb Cortex. 2016; 26(3): 1117-29. doi: 10.1093/cercor/bhu293.

16. Zhang Z, Sun QQ. Development of NMDA NR2 subunits and their roles in critical period maturation of neocortical GABAergic interneurons. Dev 
Neurobiol. 2011; 71(3): 221-45. doi: 10.1002/dneu.20844.

17. Yuan K, Fink KL, Winer JA, et al. Local connection patterns of parvalbumin-positive inhibitory interneurons in rat primary auditory cortex. Hear Res. 2011; 274(1-2): 121-8. doi: 10.1016/j.heares.2010.06.014.

18. Jevtovic-Todorovic V, Absalom A, Blomgren $K$, et al. Anaesthetic neurotoxicity and neuroplasticity: an expert group report and statement based on the BJA Salzburg Seminar. Br J Anaesth. 2013; 111(2): 143-51. doi: $10.1093 /$ bja/aet177.

19. Zheng $\mathrm{H}$, Koo $\mathrm{EH}$. The amyloid precursor protein: beyond amyloid. Mol Neurodegener. 2006; 1: 5. doi: 10.1186/1750-1326-1-5.

20. Kohli BM, Pflieger D, Mueller LN, et al. Interactome of the amyloid precursor protein APP in brain reveals a protein network involved in synaptic vesicle turnover and a close association with Synaptotagmin-1. J
Proteome Res. 2012; 11(8): 4075-90. doi: 10.1021/pr300123g.

21. Leyssen M, Ayaz D, Hebert SS, et al. Amyloid precursor protein promotes post-developmental neurite arborization in the Drosophila brain. EMBO J. 2005; 24(16): 2944-55. doi: 10.1038/sj.emboj.7600757.

22. O'Brien RJ, Wong PC. Amyloid precursor protein processing and Alzheimer's disease. Annu Rev Neurosci. 2011; 34: 185-204. doi: 10.1146/annurevneuro-061010-113613.

Correspondence to Mohanad S. Najm E-mail: mohanad.suhail@yahoo.com Received Sep. $13^{\text {th }} 2017$ Accepted Dec. 26 2017 